\title{
BENEFITS OF LOW-POWER STATIONARY PLASMA THRUSTER PROPULSION FOR SMALL SATELLITES
}

\author{
Craig W. Clauss \\ Atlantic Research Corporation, Aerospace Group, Gainesville, VA
}

Dennis L. Tilley, David A. Barnhart

Air Force Phillips Laboratory, Edwards AFB, CA

\begin{abstract}
The paper examines some of the benefits to be gained in using Stationary Plasma Thruster (SPT) propulsion onboard small spacecraft. SPTs were developed in Russia, and have an extensive flight history, with over 70 thrusters flown since 1971. A joint venture company is qualifying a complete propulsion subsystem incorporating Russian thrusters with western electronics and propellant feed components. The availability of thrusters which operate with input powers under 500 watts, as well as the simple, compact design of the SPT makes it well suited for application on small satellites. An interplanetary mission proposed to NASA's Middle Explorer (MIDEX) program, uses SPT primary propulsion to achieve its mission goals. A detailed preliminary design of the system has been prepared, showing that a compact SPT propulsion subsystem easily integrates into a $200 \mathrm{~kg}$ carrier spacecraft. Several other application could benefit from using a SPT providing increased utility or reducing overall mission costs.
\end{abstract}

\section{$\underline{\text { Introduction }}$}

In the 1990's both commercial and government programs are seeking low-cost solutions to their orbital communication, observation and scientific needs. Advances in technology and diminishing budgets have combined, leading to a revolution in small satellites. With the advent of small satellites, the cost of placing a payload in orbit has become a large fraction of total program costs. Electric propulsion, using Stationary Plasma Thruster (SPT) technology, enhances the capabilities of satellites and launch vehicles.
This paper will provide a brief overview of electric propulsion devices. A history of the SPT and its application onboard Russian satellites will be given followed by efforts underway today to make this device available in the west. A description of the stationary plasma thruster and its related propulsion subsystems will follow.

An example of an application where SPT propulsion benefits small satellite missions is presented. An interplanetary mission which involves the deployment of six microsatellites is examined in detail. This mission has been proposed as a MIDEX mission and uses two SPT70 thrusters for primary propulsion. A detailed examination of the propulsion system design for this module is presented. Finally, other mission scenarios are suggested where SPT propulsion provides increased utility or reduced mission cost to the satellite user.

\section{Background}

Electric propulsion devices use electrical energy to achieve high specific impulse by either heating a propellant and expanding out of a nozzle, or directly accelerating particles with electromagnetic body forces. There are three classes of electric propulsion devices: electrothermal, electrostatic and electromagnetic. Electrothermal devices heat a propellant gas using resistive heating, or an electric arc, producing higher exhaust velocities than chemical engines. Resistojets and arcjets are in this category and have been successfully flown on various government and commercial satellites. ${ }^{1}$ The second category of devices, electrostatic, produce thrust by accelerating charged particles, typically xenon gas ions, through an electric field. This group includes ion engines several designs of which 
are being qualified by various organizations. Electromagnetic devices include

Magnetoplasmadynamic (MPD) thrusters, pulsed plasma thrusters (PPT) and Hall-effect thrusters of which the stationary plasma thruster is a member. These devices use the $J \times$ B Lorenz force, to accelerate propellant particles.

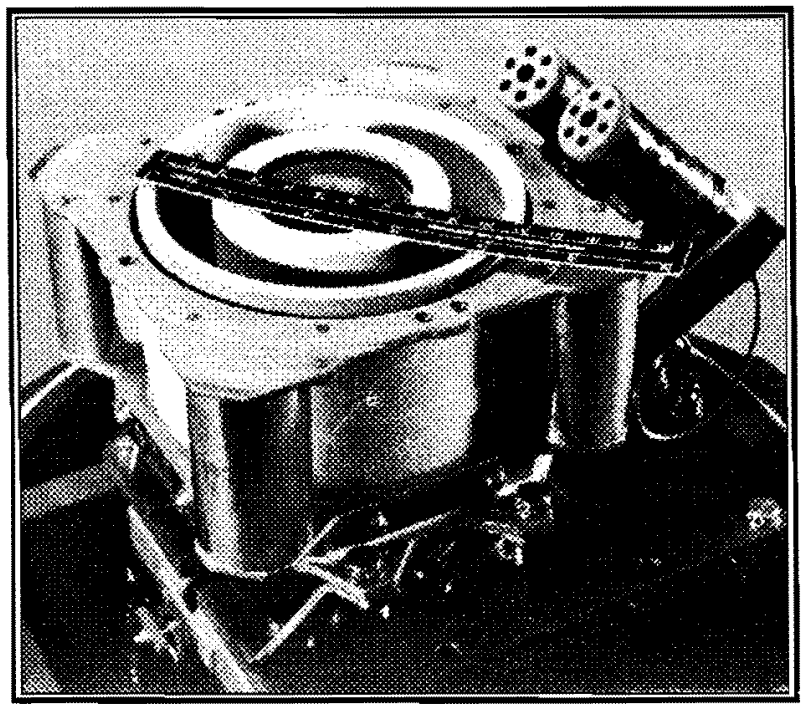

Figure 1. SPT-100

All three classes of electric propulsion offer superior specific impulses compared to stateof-the-art chemical thrusters. Since propellant mass is typically a substantial fraction of a spacecraft's total mass, any boost in "fuel efficiency" will mean higher payload mass fractions and often the ability to use a smaller, less expensive launch vehicle.

Electrothermal devices operating on hydrazine propellant are commercially available today, offering increases in specific impulse ranging from 1.3 to 2.8 times that of hydrazine propulsion $(220 \mathrm{sec} .)^{2}$ Ion engines offer specific impulses in excess of 3,000 seconds, but have heavier subsystem component requirements and tend to be large in volume. ${ }^{3}$ MPD thrusters and PPTs are not yet well developed, although; several PPTs have flown performing unique missions. ${ }^{4}$

The SPT offers a compromise between the arcjet and ion engine. Its nominal specific impulse of about 1,600 seconds is seven times that of hydrazine. Specific impulses in the 1,000-2,000 second range, are near optimal for near-Earth type missions; higher specific impulses than tend to give diminishing returns for this class of mission. ${ }^{5}$ The high thrust density of the device relative to ion engines allows for easy integration on small satellites. A more detailed examination of the SPT, its performance, and subsystem is presented in the next section.

\section{Stationary Plasma Thruster}

\section{$\underline{\text { History }}$}

Developed by Russian scientists and engineers in the late 1960 's, over 70 SPT thrusters have operated in space with a $100 \%$ mission success rate. The first SPT thruster flight, using an SPT-60, was launched in 1971 on a low Earth orbit satellite of the Meteor series in the former Soviet Union. Several other early SPT flights involved the SPT-60 and SPT-50 on other LEO spacecraft. ${ }^{\circ}$ Later in the 1980's, SPT-70s served as East-West stationkeeping thrusters for the Kosmos series geostationary communication satellites.

Table 1. SPT Flight History

\begin{tabular}{|l|c|c|c|}
\hline Spacecraft & $\begin{array}{c}\text { Thruster } \\
\text { Type }\end{array}$ & $\begin{array}{c}\text { Launch } \\
\text { Date }\end{array}$ & Mission \\
\hline Meteor & SPT-60 & $12 / 30 / 71$ & $\begin{array}{c}\text { First Flight } / \text { Perf. } \\
\text { Verification }\end{array}$ \\
\hline Meteor & SPT-60 & $7 / 9 / 74$ & Test Flight / EMI \\
\hline Meteor & SPT-50 & S/5/76 & Experiments \\
\hline Kosmos & SPT-70 & $5 / 18 / 82$ & Communication Sat. \\
\hline Kosmos & SPT-70 & $3 / 2 / 84$ & Communication Sat. \\
\hline Kosmos & SPT-70 & $4 / 4 / 86$ & Communication Sat. \\
\hline Kosmos & SPT-70 & $10 / 1 / 87$ & Communication Sat. \\
\hline Kosmos & SPT-70 & $8 / 2 / 88$ & Communication Sat. \\
\hline Kosmos & SPT-70 & $9 / 19 / 90$ & Communication Sat. \\
\hline Kosmos & SPT-70 & $12 / 11 / 91$ & Communication Sat. \\
\hline Luch & SPT-70 & $10 / 10 / 85$ & Communication Sat. \\
\hline Luch & SPT-70 & $11 / 26 / 87$ & Communication Sat. \\
\hline Luch & SPT-70 & $12 / 27 / 88$ & Communication Sat. \\
\hline Kosmos & SPT-70 & $2 / 2 / 87$ & Topaz Reactor Test \\
\hline Kosmos & SPT-70 & $7 / 10 / 87$ & Topaz Reactor Test \\
\hline
\end{tabular}




\begin{tabular}{|c|c|c|c|}
\hline Kosmos & SPT-70 & $1 / 26 / 94$ & Communication Sat. \\
\hline Kosmos & SPT-70 & $10 / 10 / 94$ & Communication Sat. \\
\hline GALS & SPT-100 & $1 / 26 / 94$ & Communication Sat. \\
\hline EXPRESS & SPT-100 & $10 / 10 / 94$ & Communication Sat. \\
\hline
\end{tabular}

In 1994, the first 16 SPT-100 thrusters were launched on the Russian communication satellites GALS and EXPRESS. These thrusters are currently performing both East-West and North-South stationkeeping on these satellites. Additionally, SPT-70s continue to be used on the Kosmos series spacecraft in Russia. All flight SPTs have been developed and manufactured by the Experimental Design Bureau Fakel located in Kaliningrad Oblast, Russia.

\section{Western Involvement}

Following the breakup of the Soviet Union, information became available to the western world about the SPT. The SPT's exceptional flight experience, high reliability and performance characteristics sparked interest in many western organizations. ${ }^{7,9,9}$ Various groups set out to verify performance claims and gain a better understanding of this technology. ${ }^{10}$

A Joint Venture company, International Space Technology, Inc. (ISTI) was formed in 1992 which included Space Systems/Loral (SS/L), Fakel and the Research Institute of Applied Mechanics and Electrodynamics (RIAME). Later the French Société Européene de Propulsion (SEP) and Atlantic Research Corporation (ARC) joined taking responsibility for marketing of ISTI subsystems in Europe and the U.S. respectively.

ARC through its partnership in ISTI, is making ISTI developed propulsion systems available to the U.S. satellite community. ISTI propulsion systems incorporate flight proven Russian SPT thrusters and SS/L designed power electronics. A complete propulsion subsystem has been developed and is in the final stages of qualification to western standards. ${ }^{11}$

Today a SPT -100 subsystem is being qualified for future application on SS/L communication satellites. ${ }^{12}$ The French technology satellite program Stentor has baselined SPT propulsion for North-South stationkeeping. ${ }^{13}$ SPT70 thrusters have been proposed as main propulsion for the MIDEX class mission Energetic Transient Array (ETA). A more detailed examination of the propulsion system for ETA will be covered in a later section.

\section{SPT Description and Operation}

The stationary plasma thruster is a closeddrift extended acceleration Hall thruster. It produces thrust by ionizing xenon gas and accelerating it to high exhaust velocities through an electric potential between the annular anode and the exit plane of the thruster.

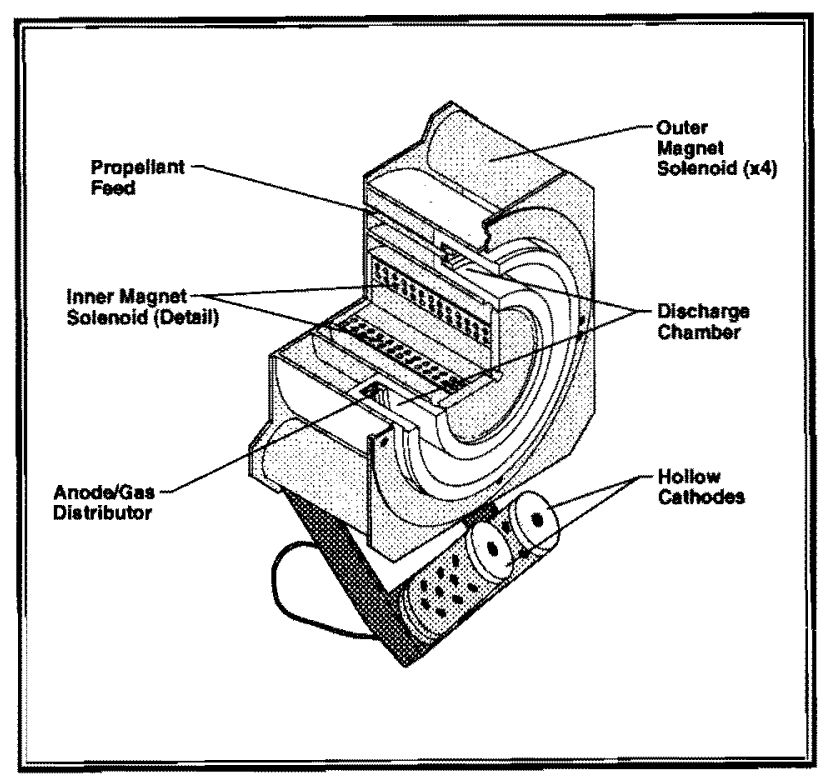

Figure 2. SPT Cutaway

The cutaway figure 2 above highlights the primary elements of the thruster: two redundant hollow cathodes, an anode/gas distributer, a ceramic discharge chamber and the magnetic system.

During thruster operation, one of the redundant hollow cathodes provides a source of free electrons for the plasma, as well as to neutralize the ionized exhaust of the thruster. The hollow cathode has a $\mathrm{LaH}_{6}$ insert that when heated produces electrons by thermionic emission from its surface. About $8 \%$ of the total thruster propellant flow is diverted to the cathode and is essential to its operation. The cathode also contains a 
resistance heater, and ignitor circuit used for thruster start up.

A ceramic discharge chamber is used to isolate the plasma from the metallic parts of the thruster. The ceramic is composed primarily of Boron Nitride and $\mathrm{SiO}_{2}$. The annular shape of the discharge chamber accommodates the $\mathrm{E} \times \mathrm{B}$ drift motion of the electrons in the azimuthal direction, hence the name closed drift. During normal operation the outer portions of the insulator act as a wear surface due to impact of spurious plasma ions.

A metallic annular ring placed at the back of the discharge chamber acts in the dual role of anode for the main discharge, and part of the xenon feed system. Many small holes machined in the ring and shielded from the plasma, permit xenon gas to evenly bleed into the annular discharge chamber.

Four outer solenoid magnets and one inner solenoid magnet provide the necessary magnetic field to facilitate operation of the thruster. Metallic pole pieces concentrate the magnetic field at the exit of the annular discharge chamber of the thruster. The strong magnetic field in this region acts to impede the drift of electrons from the cathode to the positively charged anode. The solenoid magnets are in series with the main discharge; thus during normal operation only a single power supply is needed.

The xenon gas emitted from the gas distributer drifts towards the exit of the discharge chamber. In the region of the exit plane, the strong magnetic field has trapped fast-moving electrons from the cathode which collide with the xenon atoms, to produce a xenon ion. Once ionized, the positively charged xenon ion is repulsed by the positively charged anode and is ejected from the discharge chamber producing thrust.

\section{Family of SPTs}

As shown in table 1, a variety of SPTs have flown missions. The focus of ISTI's efforts to date have revolved around the western qualification of the SPT-100. The number 100 refers to the outer diameter of the annular discharge chamber in millimeters. This thruster produces 0.083 newtons thrust with 1350 watts of electrical input power which is well suited for operation on modern geostationary communications satellites. ${ }^{14}$

ISTI has undertaken an extensive qualification and characterization program since its creation in 1992. Two SPT-100 thruster life tests have been successfully completed. These tests, one at NASA's Jet Propulsion Laboratory and another at Fakel, have demonstrated over 5,700 and 7,300 hours respectively, before. Both thrusters were operational at the end of the tests. ${ }^{11}$

Characterization tests covering all aspects of thruster operation, including: radiated electromagnetic interference, plume properties, interactions with spacecraft materials, thermal and

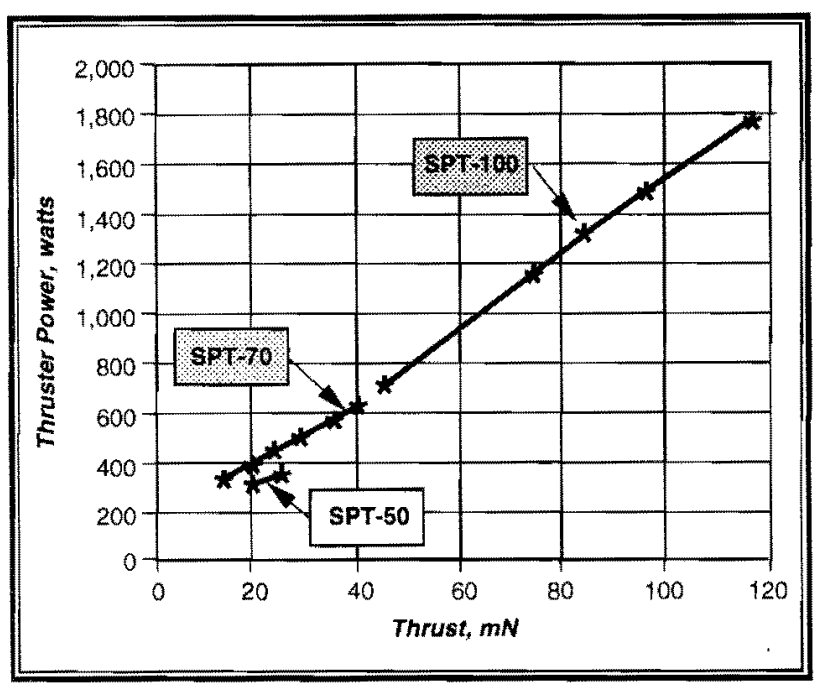

Figure 3. SPT Power vs. Thrust

structural tests as well as thruster life have been verified in facilities in the U.S.A., Russia and France. Several papers cover the details of these tests and their results. ${ }^{11,15,16,17,18,19}$

Much of what has been learned about the SPT-100 can also be applied to the SPT-70 and even the SPT-50. One of the features of the SPT class of thrusters is the scalability of the design. Figure 3 shows how the power and thrust scales for the SPT. In the case of small satellites, power is likely to be limited, so a lower power SPT is desirable. The SPT-70 has the most extensive flight history and is able to operate efficiently at power levels below 600 watts. 
Table 2. Nominal SPT Performance

\begin{tabular}{|c|c|c|c|}
\hline \multicolumn{4}{|c|}{ Operating Conditions } \\
\hline Parameter & SPT-100 & SPT-70 & SPT-50 \\
\hline $\begin{array}{l}\text { Propellant } \\
\text { Discharge Voltage } \\
\text { Discharge Current } \\
\text { Discharge Power } \\
\text { Propellant Flow Rate } \\
\text { Thruster Mass }\end{array}$ & $\begin{array}{c}\text { Xenon } \\
300 \text { Volts } \\
4.5 \text { Amps } \\
1,350 \text { Watts } \\
5.3 \mathrm{mg} / \mathrm{s} \\
3.5 \mathrm{~kg}\end{array}$ & $\begin{array}{l}\text { Xenon } \\
300 \text { Volts } \\
2.17 \text { Amps } \\
650 \text { Watts } \\
2.7 \mathrm{mg} / \mathrm{s} \\
1.5 \mathrm{~kg}\end{array}$ & $\begin{array}{l}\text { Xenon } \\
200 \mathrm{Volts} \\
1.5 \text { Amp } \\
300 \mathrm{Watts} \\
1.5 \mathrm{mg} / \mathrm{s}^{*} \\
0.6 \mathrm{~kg}\end{array}$ \\
\hline \multicolumn{4}{|c|}{ Nominal Performance } \\
\hline Characteristic & SPT-100 & SPT-70 & SPT-50 \\
\hline $\begin{array}{l}\text { Thrust } \\
\text { Specific Impulse } \\
\text { Efficiency } \\
\text { Total Impulse } \\
{ }^{*} \text { Cathode flow not included }\end{array}$ & $\begin{array}{c}.083 \mathrm{~N}(.019 \mathrm{lbf}) \\
1,600 \mathrm{sec} . \\
.48 \\
>1,000,000 \mathrm{~N}-\mathrm{s} \\
(225,000 \mathrm{lbf}-\mathrm{s})\end{array}$ & $\begin{array}{c}.040 \mathrm{~N}(.009 \mathrm{lbf}) \\
1,510 \mathrm{sec} \\
.46 \\
>400,000 \mathrm{~N}-\mathrm{s} \\
(90,000 \mathrm{lbf}-\mathrm{s})\end{array}$ & $\begin{array}{c}.019 \mathrm{~N}(.0043 \mathrm{lbf}) \\
1,280 \mathrm{sec}^{*} \\
0.40^{*} \\
>140,000 \mathrm{~N}-\mathrm{s} \\
(32,000 \mathrm{lbf}-\mathrm{s})\end{array}$ \\
\hline
\end{tabular}

In table 2, nominal operating parameters for the SPT-100, 70 and 50 are shown. Operation of the thruster off its nominal operating point is possible, but needs to be examined on a case-bycase basis since the unit is qualified at a single operational point.

The desire to have a modem thruster which is capable of operation in the 300 watt range has sparked a development effort for a new SPT50. ARC is currently under contract to NASA Lewis Research Center to deliver a laboratory model SPT-50N for test in the fall of 1995. This thruster will incorporate several novel features which will improve the performance of the thruster relative to earlier designs. As this paper will show a low-power SPT can offer the small satellite community access to the benefits of high specific impulse devices.

\section{$\underline{\text { Propulsion System }}$}

A complete propulsion subsystem has been developed by ISTI around the SPT. A pressure regulated xenon propellant feed and storage system has been designed, as well as an electrical interface with the spacecraft power bus. The subsystem components are designed to be flexible for application to various missions with minimal nonrecurring design effort. Attention has been paid to minimizing component mass while maintaining a high level of redundancy leading to a lightweight, reliable system.

The diagram in Figure 4 shows an exploded view of a complete propulsion system with two SPT-70 thrusters. The components include:

Stationary Plasma Thruster (SPT-70) - An individual thruster unit with two redundant hollow cathodes, and insulated plasma discharge/thrust chamber, anode/gas distributor, magnets and poles

Xenon Flow Controller (XFC) - This device regulates propellant flow to the thruster and operating cathode. Operation of the device is controlled by the Power Processing Unit.

Power Processing Unit (PPU) - Contains all the power electronics necessary for operation of the SPT and XFC. Handles all thruster starting and operational logic, telemetry, and power conditioning. The unit features total internal redundancy with no single point failures. 


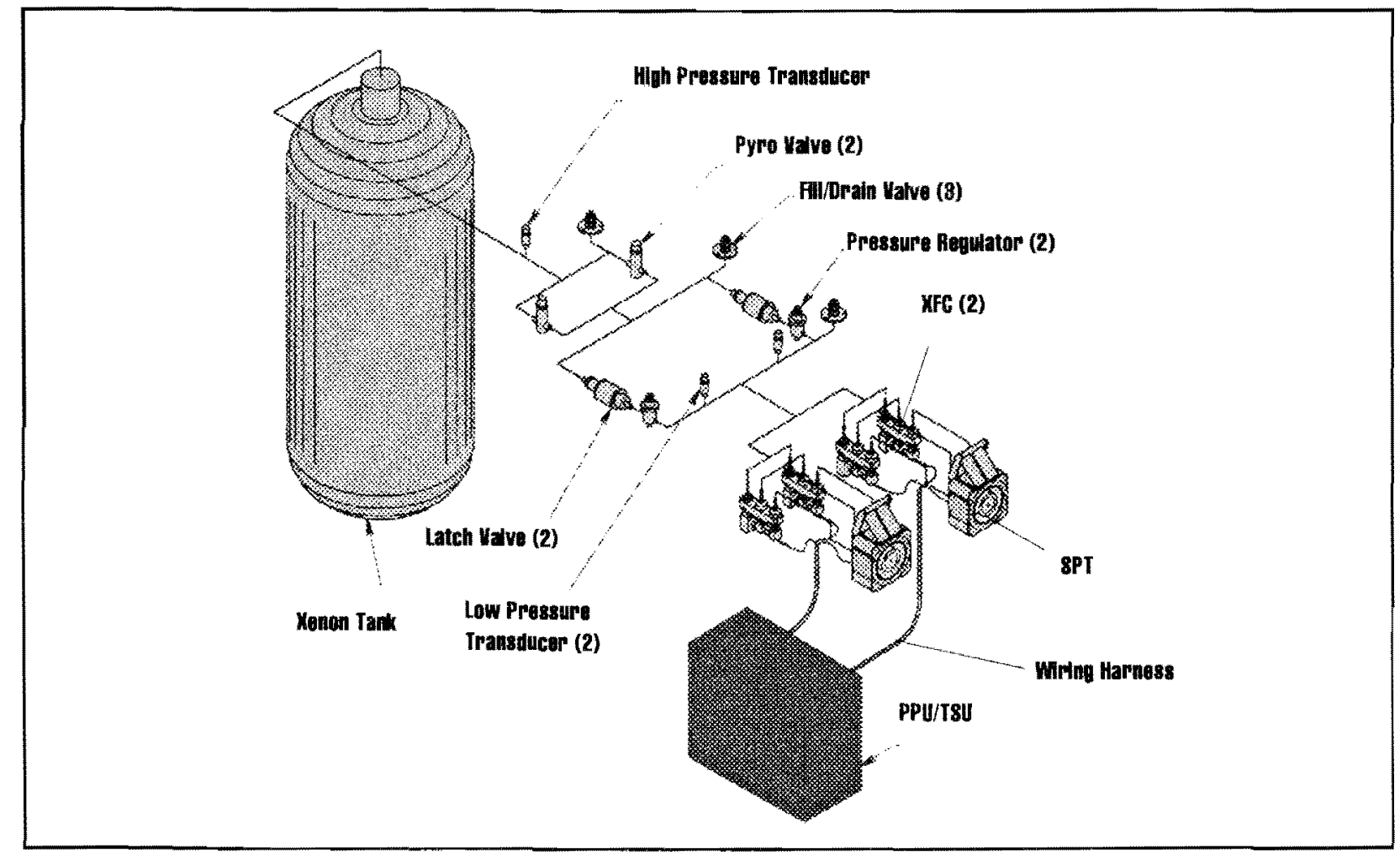

Figure 4. SPT Propulsion System

Thruster Selection Unit (TSU) - A set of redundant relays that allow one PPU to cold switch between two SPTs.

Propellant Management Assembly (PMA) - This subsystem provides isolation of propellant tanks during launch, pressure regulation, monitoring and delivery of propellant to the XFCs.

Propellant Tanks - Composite overwrapped pressure vessel used to store xenon propellant sized to fit mission needs.

\section{SPT Advantages}

There are various electric propulsion devices commercially available and in different stages of development. The stationary plasma thruster offers several unique features which make it attractive for application on small satellites.

In addition to the extensive flight heritage of the SPT and its $100 \%$ mission success rate the following design features greatly enhance the utility of this thruster for small satellites.

- Offers higher specific impulse than electrothermal and chemical thrusters.

- Simplicity of design minimizes the need for heavy support electronics.

- Availability of thrusters operating from under 300 to 1,400 watts of input power.

- Built-in redundancy of the cathode enables one to fly a single thruster with reasonable reliability.

- Long life demonstrated in several tests.

- Xenon propellant is inert, easily storable, and reduces ground handling costs associated with chemical propellants.

- High thrust density relative to ion engines leads to a compact thruster design. 
- Operation at low voltages and no need for separate magnet supplies leads to a lighter power supply design.

\section{ETA Mission Propulsion System}

\section{$\underline{\text { Mission Background }}$}

The Energetic Transient Array or ETA mission is a concept developed by the Center for Space Research of the Massachusetts Institute of Technology (MTT). ${ }^{20}$ This mission proposal has been submitted by MIT as a candidate for flight under NASA's Middle Explorer (MIDEX) program. The goal of ETA is to deploy a constellation of six microsatellites equipped with gamma-ray detectors, in a heliocentric orbit at approximately one AU radius. The microsatellites will spread out in a 120 degree arc during the first two years after launch. The network of microsatellites would measure gamma-ray burst phenomenon and allow accurate determination of their position. The origin of these gamma-ray bursts cannot be determined with information available today. With precise positional information provided by ETA, the high energy bursts can be examined with instruments onboard Hubble Space Telescope, AXAF, and SIRTF.

A provision of the MIDEX class missions is launch on board NASA's Mid-Lite vehicle. The Mid-Lite is limited to placing $580 \mathrm{~kg}$ of payload on an Earth escape trajectory. ${ }^{21}$ To deploy the constellation of 6 microsatellites in the a carrier vehicle is used. In order to meet the mass requirements dictated by the launch vehicle the decision was made to use an SPT propulsion system onboard the carrier. In the ETA mission proposal, the principle investigator is the MIT Center for Space Research, with the microsatellites and carrier being built by Orbital Science Corporation (OSC) and the SPT propulsion module being designed and integrated by the Air Force Phillips Laboratory. Atlantic Research Corporation would support Phillips Lab's efforts with the propulsion system as would the NASA Lewis Research Center.

\section{$\underline{\text { Mission Requirements }}$}

There were several constraints placed upon the mission which lead to the final design. The major requirements along with a brief explanation of their basis follows. ${ }^{22}$

- Angular spread of 120 degrees in 2 years This constraint evolved from limitations on the hardware life, resolution requirements for determination of gamma burst location, and programmatic costs. The velocity increment, $\Delta V$, for the carrier can be determined from this constraint.

\section{- Launch on a Med-Lite vehicle} Use of the Med-lite launch vehicle, is set in NASA's MIDEX mission scenarios. This vehicle will deliver a $560 \mathrm{~kg}$ payload to an Earth escape trajectory with a specific kinetic energy $C_{3}$ of $1,000 \mathrm{~m}^{2} / \mathrm{sec}^{2}$. When the mass of the microsatellites and the fixed mass of the carrier is subtracted from this, the amount of mass available to the propulsion system can be determined.

\section{- Minimum number of Microsatellites set at 4} In order to accurately determine the location of the gamma-ray bursts at least four microsatellites are necessary. Additionally, an upper bound is placed on the number by the maximum payload ability of the launcher.

Several other requirements factored in including, overall system reliability, cost of hardware and programmatics, and availability. These elements were all taken into account when choosing a propulsion system for the carrier spacecraft.

\section{Thruster Selection}

All propulsion options were considered for the mission: solid, liquid and electric. It was assumed that the first microsatellite is deployed immediately after escape without any imparted $\Delta V$ from the carrier vehicle. To fulfill the first mission requirement of a 120 degree arc in two years, it was calculated that the net $\Delta V$ required is approximately $1,650 \mathrm{~m} / \mathrm{s}^{22}$ This is the velocity difference between the first microsatellite deployed and the last.

Since this is a substantial $\Delta V$, the mass of the propellant required for the various propulsion options can be significant. The mass of the 
payload varies incrementally as each microsatellite is deployed. Modification to the rocket equation incorporating the change in payload mass is performed and the assumption of equal $\Delta V$ increments for each microsatellite is made.

$$
M_{a(j+1)}=M_{c a r r i e r}+(N-j) M_{\mu, s a t}+\sum_{i=j+1}^{N} M_{p r o p(i)}
$$

In equation $1, M_{a(j+1)}$ is the final mass after a given burn $j, M_{\text {carrier }}$ is the dry mass of the carrier, $\mathbf{M}_{\mu \mathrm{sat}}$ is the wet mass of an individual microsatellite, and $\mathrm{M}_{\text {prop(i) }}$ is the propellant weight for burn $i$ which is given in equation 2 .

$$
M_{p r o p}(i)=M_{a(i+1)}\left[\exp \left(\frac{\Delta V_{\mu s a t}}{g I_{s p}}\right)-1\right]
$$

Equation 2 is the propellant mass associated with a given burn $i$. In this equation $I_{s p}$ is the specific impulse of the propulsion system, $\Delta V_{\text {pasat }}$ is the total $\Delta V$ divided by the number of microsatellites and $\mathrm{g}$ is gravitational acceleration at the surface of the Earth. The total carrier propellant mass is computed by summing the propellant associated with each burn. Equation 3 shows this summation over $\mathrm{N}$ microsatellites.

$$
M_{\text {prop }}=\sum_{j=1}^{N-1} M_{p r o p(j)}
$$

Calculation of propellant mass is made by iteration of the above equations. A fixed value for the microsatellite mass of $50 \mathrm{~kg}$ was set by systems designers. The carrier, which contains structure, spacecraft computers, solar array and power bus, communications, a small cold gas ACS system and the dry mass of the main propulsion system was fixed at $200 \mathrm{~kg}$.

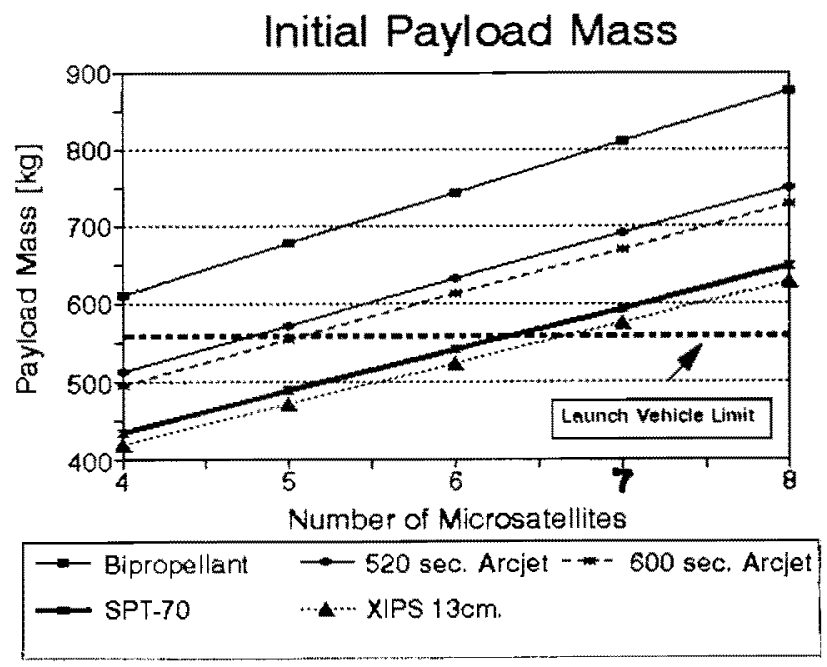

Figure 5. Launch Mass vs. Propulsion System

Figure 5 shows a comparison of initial launch mass required to deploy the constellation with a $1,650 \mathrm{~m} / \mathrm{s} \Delta V$ with number of microsatellites, for several propulsion options. A comparison of each of the different propulsion systems was performed based on this first order analysis.

A solid system entailed individual motors for each microsatellite. This was rejected early because it required 5 separate motors, each having to provide an incrementally larger $\Delta \mathrm{V}$.

The chemical bipropellant system was ruled out because it lead to a payload mass of 600 $\mathrm{kg}$ with the minimum 4 microsatellites. Thus this system violated two of the mission requirements.

Two arcjets were examined operating with specific impulses of 520 and 600 seconds. Both of these arcjets enable the mission to be performed with the minimum 4 microsatellites, and marginally with 5 . Arcjets commercially available today with this performance require in excess of 1,800 watts of electrical power. Due to the extra cost and mass associated with higher power these thrusters were also ruled out.

The SPT-70 operating with an input power less than 700 watts proved to be well suited to the mission. Up to six microsatellites could be 


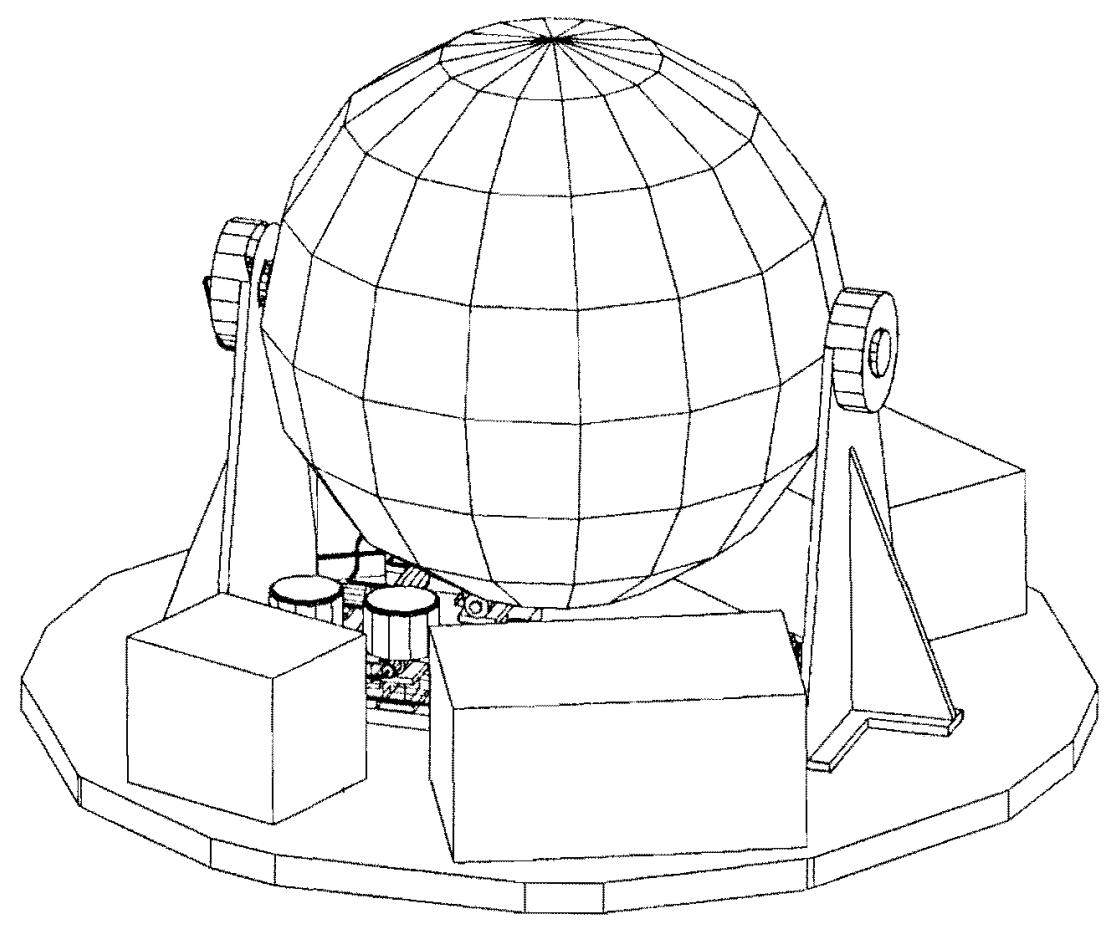

Figure 6. ETA Propulsion System

deployed using an SPT system and it was chosen for the baseline.

The higher specific impulse of the XIPS $13 \mathrm{~cm}$ ion engine, 2,585 seconds, provided only marginal benefit to propellant mass. Use of the XIPS thruster did not allow a seventh microsatellite to be deployed. Increased complexity and mass of the ion engine subsystem would also bring higher cost and dry mass to the carrier.

Using a SPT-70 to deploy six microsatellites over a $\Delta V$ of $1,650 \mathrm{~m} / \mathrm{s}$, requires about $40 \mathrm{~kg}$ of propellant, leaving $20 \mathrm{~kg}$ of mass margin, figure 5 . In the propulsion subsystem design, the propellant tanks are sized to use this margin as extra xenon propellant. By using this fuel and increasing the $\Delta \mathrm{V}$ between the microsatellites to about $2,300 \mathrm{~m} / \mathrm{s}$, the constellation will deploy much faster.

\section{Subsystem Design}

The ETA propulsion subsystem design is shown in figures 6 through 8 . The design was constrained by the interface with the carrier vehicle and the launch vehicle envelope. To facilitate ease of integration with the carrier it was decided early on to integrate the propulsion subsystem onto a circular aluminum honeycomb plate approximately 33 inches in diameter. As a result of the low xenon propellant mass required, the SPT propulsion system dry mass was not heavily constrained. Since mass was not a primary driver, cost and redundancy were focused upon. It was also important to make the system as independent of the carrier as possible, to simplify the interface requirements. A separate cold gas attitude control system is built into the carrier. This subsystem is separate from the SPT propulsion system and will not be covered here. Table 3 gives a breakdown of the propulsion subsystem dry mass.

\section{Thruster}

The SPT-70 was chosen over the SPT-100 for this mission. This decisions was based upon the lower power requirements, and the availability of the two thrusters already in inventory at the 


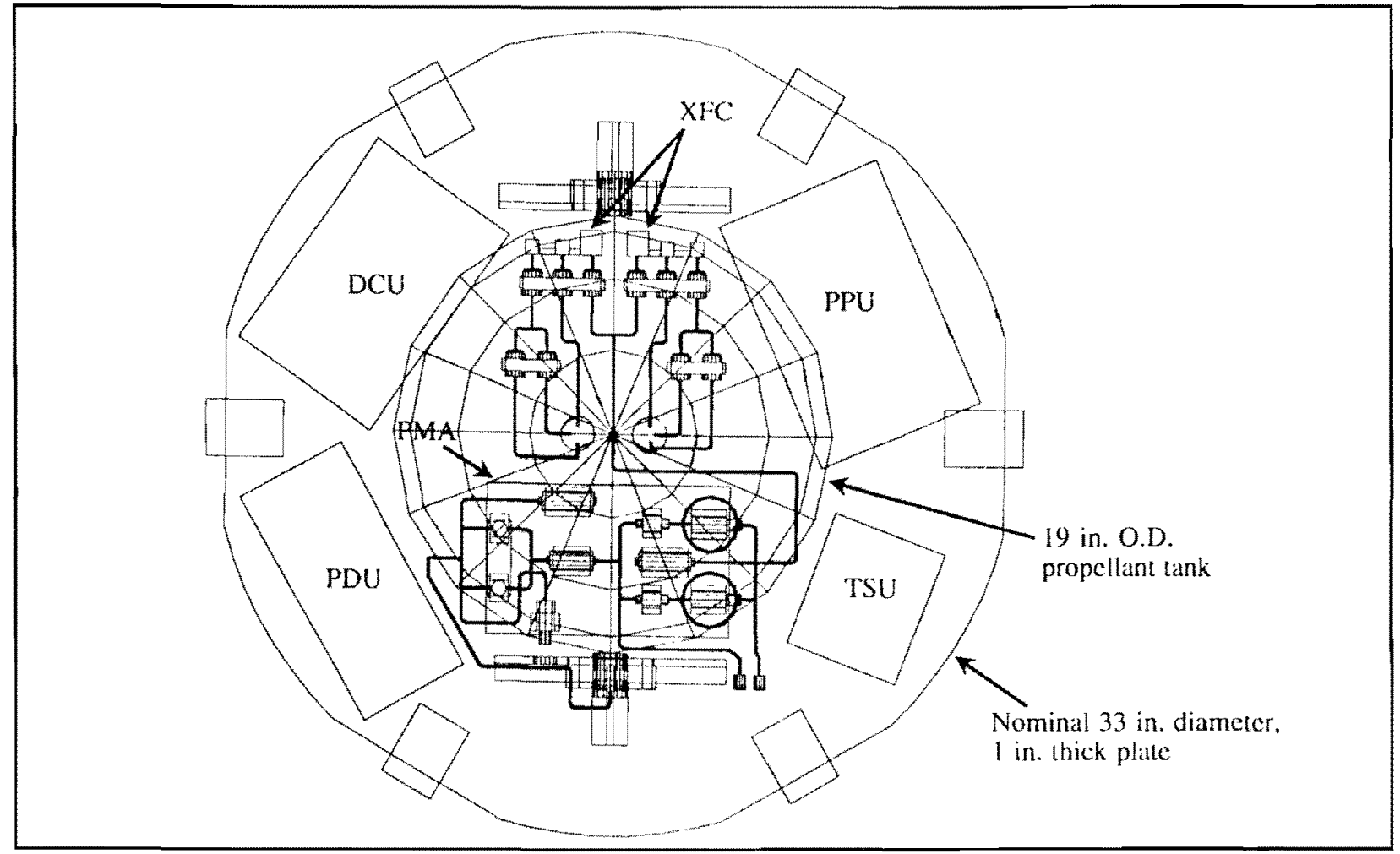

Figure 7. ETA Propulsion System (top view cutaway)

Phillips Laboratory. Two thrusters are used for redundancy, and because the total impulse required is beyond the recommended design life for an single SPT-70.

\section{Propellant Storage and Management}

Xenon propellant can be stored in a super-critical state, with densities of up to twice that of water. For this design, the maximum tank operating pressure is fixed at 2,100 psi by the pressure regulator design. Tank mass fractions on the order of $10 \%$ are achievable under these storage conditions, A low-cost, off-the-shelf tank design was desired for this application. Sizing of the tank was based upon a maximum inlet pressure of $2,100 \mathrm{psi}$ and the need to store $60 \mathrm{~kg}$ of propellant. Baselined in this design is a 19 inch O.D. graphite composite overwrapped spherical stainless steel pressure vessel built by ARDE (D4333). If necessary, heaters will be used to maintain a storage temperature greater than 17 degree Centigrade, to prevent liquefaction.

During launch the tank is isolated from the feed system by parallel redundant pyrotechnic isolation valves which are a part of the integrated Propellant Management Assembly (PMA). Developed by Moog Space Products division for ISTI, the PMA consists of a parallel redundant set of regulators, latch valves and pyrotechnic isolation valves. These items as well as three pressure transducers, and three fill/drain valves are mounted onto a plate and plumbed together as a single assembly. This provides the system integrator with a single unit to integrate into the propellant feed subsystem. The fill/drain valves can also be detached and relocated for better access. The regulator drops the pressure from a maximum of 2,100 psi down to 37 psi before entrance into the flow controllers.

\section{Xenon Flow Controllers}

After exiting the regulator, propellant enters the xenon flow controller. Normally each thruster has a its own flow controller, which is fabricated by Fakel. The flow controller serves two functions, to meter the xenon gas flow and to split the propellant feed between the anode and cathode. The current system design uses a half 
flow controller and a set of 2 latch valves per thruster rather than two complete flow controllers.

A half XFC consists of three solenoid valves, which are controlled together by the PPU, a thermothrottle and a flow restrictor. The thermothrottle uses a heated capillary tube to vary the propellant flow rate in the milligrams per second range. A flow restrictor is used to limit the flow to the operating cathode to be about $8 \%$ of the total flow to the thruster. This gas is necessary for proper function of the hollow cathode. The majority of the gas flows to the anode/gas distributor of the SPT. Each half XFC is associated with one of the two redundant cathodes on a thruster.

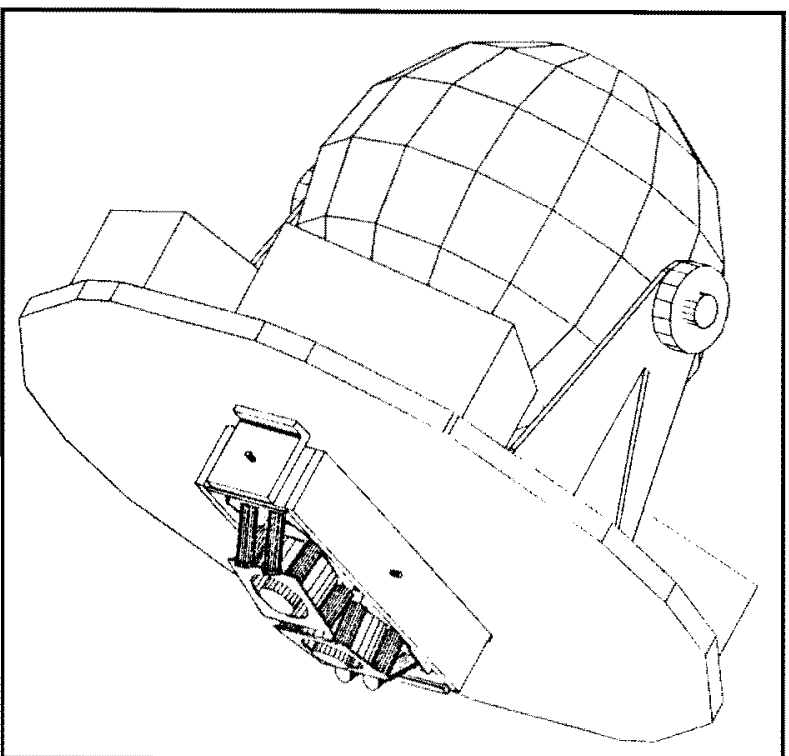

Figure 8. ETA Propulsion System (view 2)

\section{Gimbal}

A two-axis gimbal is used to adjust the SPT thrust vector to accommodate the changing spacecraft center of mass as microsatellites are dropped off as well as any drift in the thrust vector. Both thrusters share a single mechanism which is capable of +-15 degrees of motion in one direction and +-5 degrees in the other. The gimbal also provides some pitch and yaw control. At this time the gimbal design is not well defined due to the preliminary nature of the carrier design.

\section{Power Processing}

Thruster and XFC operation are controlled entirely by a Space Systems/Loral built Power Processing Unit (PPU). The SPT-70 PPU design is similar to that of the SPT-100 PPU, currently undergoing the final stages of flight qualification, with a reduction in discharge power. The SPT-70 PPU is a fully redundant modular design consisting of 8 trays each with two modules. The main discharge supply has 5 for 4 redundancy of 200 watt power modules. ${ }^{23}$

The PPU has built-in logic for controlling the startup and operation of the SPT and XFC. A discharge current set point is imputed and the PPU acts to maintain this by varying the propellant flow rate with the XFC's thermothrottle, thus producing constant thrust. Several telemetry feeds are outputted to the digital control unit.

Table 3. ETA Propulsion System Mass

\begin{tabular}{|c|c|c|}
\hline Quantity & Item & Mass \\
\hline \hline 2 & SPT-70 & 3 \\
\hline 1 & $\begin{array}{c}\text { Propellant Management } \\
\text { Assembly }\end{array}$ & 3.25 \\
\hline 1 & $\begin{array}{c}\text { Xenon Flow Controller } \\
\text { and 4 valves }\end{array}$ & 1.04 \\
\hline 1 & Propellant Tank & 11.3 \\
\hline 1 & Power Processing Unit & 6.6 \\
\hline 1 & Thruster Selection Unit & 2 \\
\hline 1 & Gimbal & 6 \\
\hline 1 & Structure / Fixtures & 5 \\
\hline 1 & Harness / Tubing & 5 \\
\hline \hline & \multicolumn{2}{|c|}{ Subtotal } \\
\hline 1 & Digital Control Unit & 4.5 \\
\hline 1 & Power Distribution Unit & 7.5 \\
\hline \hline & Total Dry Mass & 55.43 \\
\hline
\end{tabular}

Since the PPU is fully redundant, with no single point failures, the system design is able to use a single PPU with two thrusters. In order to switch between the thrusters a Thruster Selection 
Unit (TSU) is used. The TSU consists of a set of relays which can switch the output from the PPU to either of the SPTs. Only cold switching is done, without either thruster operating.

In addition to the PPU, two other devices are used to control all aspects of the propulsion system operation. Phillips lab is designing a Digital Control Unit (DCU) to interface with the spacecraft computer ${ }^{24}$ The DCU in combination with a power distribution unit (PDU), will control and power the operation of the electrical systems in the PMA, PPU, and gimbal as well as any heaters found to be necessary. The entire system should be able to operate autonomously, with the only inputs from the carrier being solar array power, thruster on/off, and telemetry.

The strategy behind the use of a DCU and power distributor is to simplify the interface between the propulsion subsystem and the main carrier spacecraft and minimize interaction with the carrier manufacturer. This will reduce costs associated with a complicated interface and communications. The slight inefficiencies in design are considered an acceptable compromise. It should be emphasized that this strategy is unique to the ETA program and is not a universal requirement for the system.

\section{Operation}

The launch vehicle places the carrier on an Earth escape trajectory with some hyperbolic excess velocity. A coasting phase of around 85 days is followed by the deployment of the first satellite. At this time the SPT is activated with a burn of about a month to place the second satellite. Since the carrier is in solar orbit the solar array is able to produce constant power for thrusting.

A maneuver is then performed to reverse the direction of the carrier, opposite of Earth's heliocentric motion, and the final burns are performed. Microsatellites are then placed in an arc with several satellites preceding the Earth and several behind it in heliocentric orbit.

\section{Status of ETA Program}

Proposals to NASA's MIDEX announcement of opportunity were submitted in June of this year. A first round downselect of 10 missions for further study is set for October of 1995. The final selection of two missions for launch as early as 1999 is slated for Spring of 1996.

\section{Other Applications}

A small interplanetary satellite constellation mission was presented above where use of an SPT enabled a robust mission within tight launch vehicle payload constraints. This type of mission is not the only class of small satellite missions which could benefit from SPTs. Various other mission requiring a substantial $\Delta \mathrm{V}$ can be accomplished with a high payload mass fraction.

\section{Constellation Deployment}

Deployment of multiple satellites which may involve orbit transfer, repositioning, small plane changes, on-orbit drag make up and deorbit maneuvers can accumulate a substantial $\Delta \mathrm{V}$. Use of onboard SPT propulsion can permit constellation designers to use less launch vehicles to deploy their satellites at a substantial savings.

\section{Secondary Payloads}

One of the difficulties of co-manifested payloads is the limitations on the orbital placement of the secondary payload. Depending upon the type of upper stage, the secondary payload could be limited to the same orbit as the primary. Use of an onboard SPT propulsion system would greatly increase the envelope of orbits achievable by the secondary payload.

\section{On-Orbit Repositioning}

Repositioning of Earth observing satellites to change the local time of day of a sun synchronous orbit is easily achievable with SPT propulsion. The ability to observe objects with different sun angles can greatly increase the utility of a remote sensing satellite.

\section{Unique Orbits}

Finally many missions thought unachievable due to large propulsion requirements need to be 
reexamined with consideration for the SPT. For example, missions such as low-altitude satellites with large drag penalties are possible.

\section{Conclusion}

Propulsion systems based on the Russian SPT are now available in the western world. The SPT is a unique and simple design, incorporating built in redundancy. Specific impulses in the range of 1,600 seconds, combined with the compact nature and availability of thruster models that operate at low power, make the SPT a strong candidate for application on small satellites.

A interplanetary mission proposed for NASA's MIDEX class makes use of an SPT-70 propulsion system as its baseline. The SPT propulsion system was chosen as best suited to performing this mission when compared with other systems commercially available today. The design of this propulsion system has been shown to be simple and flexible in nature.

Other possible scenarios including: deployment of Earth orbiting constellations, dual manifested payloads, orbital repositioning and unique orbits benefit from onboard SPT propulsion. High specific impulse permits a high payload mass fraction and the ability to perform demanding orbital maneuvers that would not be considered when using chemical propulsion.

\section{Acknowledgements}

The authors would like to acknowledge the assistance of Mr. Bhavesh Patel, Dr. Manual Martinez-Sanchez and Dr. George Ricker of MIT for the information provided on the mission requirements of ETA.

\section{References}

1. D. T. Palac, V. K. Rawlin, "Solar Electric Propulsion: A Technology for Increasing Value in the Era of Space Vehicle Downsizing," AIAA-94-3250, presented at the 30th Joint Propulsion Conference, June 1994

2. C. H. McLean, et al, "1000-Hour Demonstration of a 600-second Arcjet," AIAA95-2817, presented at the 31st Joint Propulsion
Conference, July 1995

3. J. R. Beattie, et al, "Flight Qualification of an 18-mN Xenon Ion Thruster," IEPC-93-106, presented at the 23rd International Electric Propulsion Conference, September 1993

4. Roger Myers, "Electromagnetic Propulsion for Spacecraft," AIAA-93-1086, prepared for the Aerospace Design Conference, February 1993.

5. M. J. Patterson, et al, "Experimental Investigation of a Closed-Drift Thruster," AIAA-85-2060, 1985

6. A. S. Bober, V. Kim, et al, "Russian Experience of EP Application in Space and on the Ground," AIAA-94-2737, presented at the 30th Joint Propulsion Conference, June 1994

7. L. H. Caveny, et al, "BMDO Electric Space Propulsion Program," AIAA-93-1934, presented at the 29th Joint Propulsion Conference, June 1993

8. J. W. Barnett, "A Review of Soviet Plasma Engine Development," AIAA-90-2600, presented at the 21st International Electric Propulsion Conference, July 1990

9. L. H. Caveny and R. J. Vondra, "Ion Propulsion Goals for Earth Orbit Transfer or the Pursuit for Low Specific impulse," AIAA90-2621, presented at the 21st International Electric Propulsion Conference, July 1990

10. J. R. Brophy, et al, "Performance of the Stationary Plasma Thruster: SPT-100," AIAA92-3155, presented at the 28th Joint Propulsion Conference, July 1992

11. M. Day, N. Maslennikov, et al, "SPT-100 Subsystem Qualification Status," AIAA-952666, presented at the 31st Joint Propulsion Conference, July 1995

12. T. Foley, "Satellite 'Technology Decades of Development Pay Off," Via Satellite, July 1995.

13. "SPT plasma thrusters slated for duty on Stentor," Sep 5 Newsletter, Number 31 
14. D. Pidgeon, C. Hoeber, M. Day, "Systems Benefits and Satellite Accommodations of the Stationary Plasma Thruster, SPT," AIAA-941008 , presented at the 15 th International Communications Satellite Systems Conference, February, 1994

15. T. Randolph, E. Pencil, "Far-Field Plume Contamination and Sputtering Characterization of the Stationary Plasma Thruster," AIAA-942855 , presented at the 30th Joint Propulsion Conference, June 1994

16. NASA Lewis Research Center, "SPT-100 Plasma Thruster Radiated EMI Test Results," unpublished report May, 1993

17. D. H. Manzella, "Stationary Plasma Thruster Plume Emissions," IEPC-93-097, presented at the 23rd International Electric Propulsion Conference, September 1993

18. S. K. Absalamov, et al, "Measurements of Plasma Parameters in the Stationary Plasma Thruster (SPT-100) Plume and its Effect on Spacecraft Components," AIAA-92-3156, presented at the 28th Joint Propulsion Conference, July 1992

19. R. M. Myers, D. H. Manzella, "Stationary Plasma Thruster Plume Characteristics," IEPC93-096, presented at the 23rd International Electric Propulsion Conference, September 1993

20. George R. Ricker, "The Energetic Transient Array -ETA- A Network of "Space Buoys" in Solar Orbit for Observations of Gamma-Ray Bursts," High Energy Astrophysics in the 21st Century, Am. Inst. of Physics 1990, pp. 375387

21. NASA Announcement of Opportunity: Medium-class Explorer Missions (MIDEX, AO-95-055-02, Appendix A, "The NASA Med-Lite Expendable Launch Vehicle," March 27, 1995

22. Bhavesh Patel, "Systems Analysis for an Astrophysics Mission Utilizing Electric Propulsion," M.S. Thesis, Massachusetts Institute of Technology, Dept. of Aeronautics and Astronautics, 1995
23. G. Fischer, et al, "Design of a High Efficiency Power Processor for the Russian Stationary Plasma Thruster," IEPC-93-043, presented at the 23rd International Electric Propulsion Conference, September 1993

24. D. A. Barnhart, et al, "Electric Propulsion Integration Activities on the MSTI Spacecraft," IEPC-93-011, presented at the 23rd International Electric Propulsion Conference, September 1993

\section{Author's Biography}

Mr. Craig W. Clauss is the electric propulsion marketing manager for Atlantic Research Corporation (ARC), in Gainesville Virginia. He received his Bachelors of Science in aeronautical engineering from Rensselaer Polytechnic Institute in 1991, and a Masters of Science, Engineering in aerospace engineering from the University of Michigan in 1992. While at Michigan, Craig was responsible for conversion of Bendix Aerospace's, 20 - 27 foot space simulation chamber into an electric propulsion test facility, and the subsequent testing of a $1 \mathrm{kw}$ arcjet thruster. Before coming to ARC, Craig worked for the U.S. Army Benet Labs, at the Watervliet Arsenal, NY modeling internal ballistic flow in high caliber artillery and for Computational Mechanics Corporation developing finite element CFD software for compressible, reacting flows.

Mr. Dennis L. Tilley received a B.S.A.A. (1986) and M.S.A.A. (1988) from the University of Washington and then joined the Electric Propulsion Laboratory at Princeton University. He earned a M. S. in Mechanical and Aerospace Engineering from Princeton University in 1991, and since then has been a research engineer at the Electric Propulsion Lab at the Phillips Laboratory, Edwards A.F.B., CA. He has worked on a broad range of electric propulsion technologies $(1-\mathrm{kW}$ and $30 \mathrm{~kW}$ class arcjets, pulsed and steady state MPD thrusters, Russian stationary plasma thrusters) and flight applications of electric propulsion (ESEX, MSTI and the recently proposed ETA). Research interests include many aspects related to electric propulsion, including plasma diagnostic, plasmadynamics and instabilities and arcjet ignition mechanism. His work investigating the propellant breakdown mechanisms 
in a $30-\mathrm{kw}$ arcjet provided the basis for the start circuit redesign for the ESEX flight experiment, and was also the topic of a paper for which he was awarded best paper in electric propulsion at the 1993 Joint Propulsion Conference. He is an author or coauthor of 16 conference papers and journal articles, and is a member of the AIAA Electric Propulsion Technical Committee. 